Article

\title{
Experimental Study of the Feasibility of Air Flooding in an Ultra-Low Permeability Reservoir
}

\author{
Guohui $\mathrm{Qu}{ }^{1, *}$, Yuanlin Meng ${ }^{1}$, Anqi Shen ${ }^{1}$, Yuxin Guo ${ }^{1}$, Yikun Liu ${ }^{1}$ and Yonghang Tao ${ }^{2}$ \\ 1 College of Petroleum Engineering, Northeast Petroleum University, Daqing 163318, China; \\ qhdmyl@163.com (Y.M.); anqi1986@126.com (A.S.); sygcgqb2012@126.com (Y.G.); \\ liuyikun111@126.com (Y.L.) \\ 2 Hainan Fushan Petroleum Exploration and Development Company Limited, Haikou 570100, China; \\ taoyongxing@petrochina.com.cn \\ * Correspondence: quguohui1001@126.com; Tel.: +86-459-650-3811
}

Academic Editor: Alireza Bahadori

Received: 7 August 2016; Accepted: 20 September 2016; Published: 28 September 2016

\begin{abstract}
The development effect of water flooding in an ultra-low permeability reservoir is poor due to its poor physical properties and high shale content, so an experimental study of air flooding which helps to complement energy production was carried out. Based on the Accelerating Rate Calorimeter experimental results, the crude oil of $\mathrm{N}$ block in $\mathrm{L}$ oilfield can undergo low-temperature oxidation reactions, which are the basic condition for air flooding. Three groups of experimental natural cylinder cores designed for oil displacement, water flooding and air flooding were used respectively, and the relationship between differential pressure, oil recovery, injection capacity with injection volume was investigated. It is observed that the recovery efficiency increased $2.58 \%$, the injection-production pressure difference dropped $60 \%$ and the injection capability increased $60 \%$ in the experiment of shifting air flooding after water flooding to $75 \%$ moisture content, compared with water flooding alone. It has been shown in the results that the recovery efficiency improved sharply more than water flooding, the effect of depressurization and augmented injection was obvious, and the air displacement was thus validated. We suggest that other science and technology workers should perform further tests and verify this result through numerical simulation.
\end{abstract}

Keywords: air flooding; ARC; extra-low permeable reservoir; feasibility

\section{Introduction}

The proven reserves found low and ultra-low permeability reservoirs in China account for a large proportion of the available oil and in recent years, water injection has been developed for low and extra-low permeability oil reservoirs, but it generally shows poor effects [1,2]. Many studies show that gas (including air, nitrogen, carbon dioxide, etc.) injection is an effective method to improve the development efficiency of low and extra-low permeability reservoirs [3-7], which can establish a valid driving force better than water injection. Less often considered is that most $\mathrm{CO}_{2}$ used for enhanced oil recovery (EOR) is never recovered, but is actually stored in the reservoir permanently; this long-term sequestration helps offset the greenhouse gas (GHG) emissions from burning fossil fuels [8-10]. In practice $\mathrm{CO}_{2}$ flooding cannot be carried out because of the air supply, scaling and corrosion of pipelines. $\mathrm{N}_{2}$ flooding gets more oil under the circumstances of a larger volume coefficient the same as the other gas injection volume. $\mathrm{N}_{2}$ has high compressibility and expansibility, but the preparation and transport of $\mathrm{N}_{2}$ are expensive. Air injection is more worthy of application because it is an abundant resource and low-cost [11,12], so air injection is expected to become one of the most preferred techniques in the future. 
Air displacement is mainly divided into low-temperature oxidation (LTO) and high-temperature oxidation (HTO) In-Situ combustion (ISC) is mainly used for heavy oil reservoirs, as its theory, including dry combustion and wet combustion, is complex. The preferred mechanism is HTO, whereby the heavy ingredients of crude oil such as coke are used as fuels, and the heating decreases the viscosity of crude oil to enhance the oil recovery. The use of horizontal wells for ISC to shorten the displacement distance, which is called the Toe-To-Heel Air Injection process (THAI) is also established, but the method is not adaptable to the target block due to the high cost of drilling horizontal wells. The target block usable for air flooding has thin oil, well trapped good and with a small inclination angle, and the main mechanism is LTO which can reduce oil viscosity, producing complementary energy to enhance oil recovery. Field testing of air flooding has been performed in the Yanchang oilfield, but the effect was not good because of the cross flow of low permeability fractured reservoirs. $\mathrm{N}$ block of L oilfield in the Bohai Bay basin on the other hand is an extra-low permeability sandstone reservoir without cracks. As the mechanism of air flooding is not only complex, but also has a certain operational risk, an experimental study has now been been conducted to study the feasibility of air displacement $[13,14]$.

\section{Experimental Design}

\subsection{Low Temperature Oxidation Kinetics Experiment}

An Accelerating Rate Calorimeter (ARC) is the instrument used for screening suitable conditions for injecting air into the reservoir. Under adiabatic conditions, by means of heating-waiting-retrievingtracking, then detecting the rate of increase of the instrument's internal temperature and evaluating the possibility of spontaneous combustion of crude oil under certain pressure, we can get the crude oil oxidation kinetic parameters (heat of reaction, activation energy, reaction series), determining the reaction type [15-17]. The experimental conditions were as follows: $\mathrm{M}$ calorimetric ball, $13.781 \mathrm{~g}$; M sample, $3.2 \mathrm{~g}$ (oil $1.5 \mathrm{~g}$ + particulate cores $1.5 \mathrm{~g}$ + water $0.2 \mathrm{~g}$ ); $\mathrm{C}_{\mathrm{p}}$ calorimetric ball, $0.42 \mathrm{~J} / \mathrm{g}, \mathrm{K}$ ); initial search temperature $50{ }^{\circ} \mathrm{C}$; stop search temperature $350{ }^{\circ} \mathrm{C}$; search step $10{ }^{\circ} \mathrm{C}$. The chemical reaction equations of low temperature oxidation are shown in Figure 1.

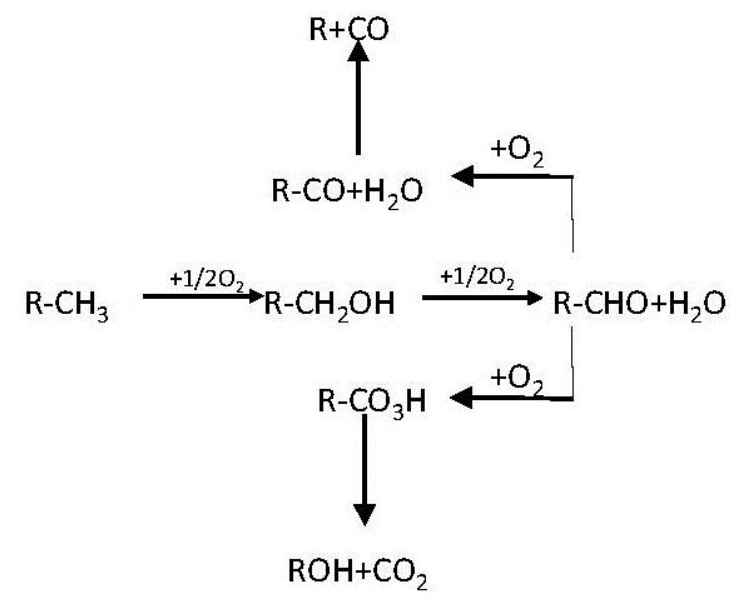

Figure 1. Chemical reaction equations of low temperature oxidation.

\subsection{Oil Displacement Experiment}

Contrastive studies of the displacement efficiency between water and gas displacement have undertaken in the $\mathrm{N}$ block of L oilfield in the Bohai Bay basin [18-22]. The block has been exposed to water flooding, thus two types of experiments were performed: direct water flooding and gas driving after water flooding, in order to get in line with the actual situation. Typical cores from producing 
wells were selected, and a series of three oil displacement experiments were designed for comparing the recovery ratio and injection capacity between the two types of displacement.

\subsubsection{Experimental Setup}

The average depth of the target block is $3100 \mathrm{~m}$, spacing is $3100 \mathrm{~m}$, the average permeability is $1 \times 10^{-3} \mu \mathrm{m}^{2}$, the average oil viscosity is $2.79 \mathrm{mPa} \cdot \mathrm{s}$, the well spacing method is an inverted nine-spot pattern, the combined water cut is $75 \%$ at present, and as the moisture content increases, the pressure of the water wells rises quickly, the stage injection-production ratio is 0.6 , and the formation energy decreased rapidly. Based on the observation of cores from inspection wells, due to the strong water sensitivity, clay expansion reduces the reservoir permeability, so gas injection is the best choice. The whole experiment was designed according to the similarity principle to simulate the reservoir.

Gas channeling can easily form because of the high permeability of gas compared with the oil and water phases. The gravity stabilization method, water/air alternate injection, air foam flooding and other ways of flooding are used in the oilfield. Considering the limited laboratory conditions, the experimental model was designed to satisfy the following conditions: first, the model is long enough, so an oxidation zone, mixed regions and oil zone can be formed after multi-level contacting; second, enough reactant is used to ensure that complete oxygen consumption happens before reaching the flue gas outlet; third, the sweep efficiency should increase along with the injection volume and amount of solvent injected; fourth, the core holding is roughed to reduce the breakthrough of injected fluid from the tube wall and improve the sweep efficiency [23]. The experimental apparatus is shown in Figure 2.

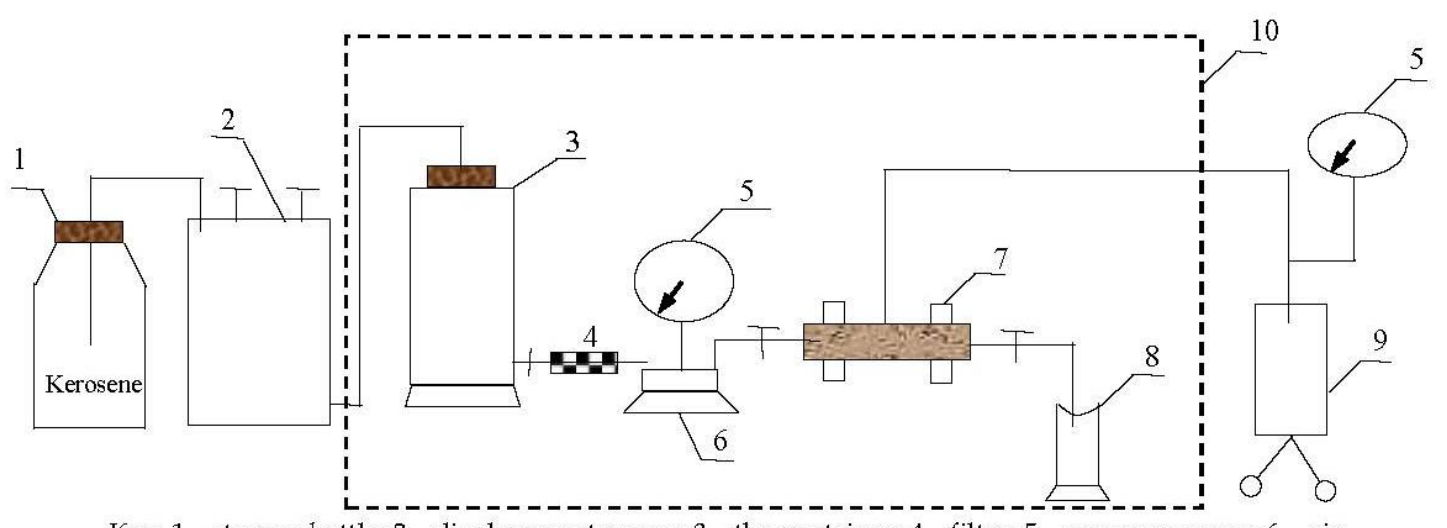

Key: 1 - storage bottle; 2 - displacement pump; 3 - the container; 4 - filter; 5 - pressure gauge; 6 - six way valve; 7 - core holder; 8 - measuring cylinder; 9 - ring pump; 10 - oven

Figure 2. Diagram of the experimental setup.

\subsubsection{Experimental Conditions}

Experimental reagents, including distilled water, $\mathrm{NaCl}, \mathrm{CaCl}_{2}, \mathrm{MgCl}_{2}$, kerosene, crude oil, air, water injection, were used etc. The cores should be long enough and not suffer damage during drilling. The basic physical parameters of the cores such as the permeability $(K)$, porosity $(\Phi)$, core length $(L)$ and diameter $(d)$ of the samples were tested after grinding, washing and drying and are listed in Table 1 . The test results show that the samples have ultra-low permeability.

Table 1. Core sample parameters.

\begin{tabular}{ccccc}
\hline Core Sample & $\boldsymbol{K} / \times \mathbf{1 0}^{-\mathbf{3}} \boldsymbol{\mu m}^{\mathbf{2}}$ & $\boldsymbol{\Phi / \%}$ & $\boldsymbol{L} / \mathbf{c m}$ & $\boldsymbol{d} / \mathbf{c m}$ \\
\hline 15 & 0.7399 & 12.63 & 6.54 & 2.36 \\
31 & 0.3279 & 10.00 & 7.09 & 2.36 \\
32 & 0.2297 & 10.00 & 6.08 & 2.36 \\
\hline
\end{tabular}


The experimental displacement oil sample is simulate the crude oil from the production well has an oil formation temperature of $78.0^{\circ} \mathrm{C}$, formation pressure is $29.0 \mathrm{MPa}$, the saturation pressure is 18.0 $\mathrm{MPa}$, dissolved gas ratio 450.0 , and crude oil viscosity is $2.79 \mathrm{mPa} \cdot \mathrm{s}$.

Experimental formation water and injected water are based on water analysis data of samples from oilfield block $\mathrm{N}$, oilfield $\mathrm{L}$. The block formation water contains sodium bicarbonate $\left(\mathrm{NaHCO}_{3}\right)$, the total salinity has an average of $5112.42 \mathrm{mg} / \mathrm{L}$, which includes high levels of cations like $\mathrm{Na}^{+}$and $\mathrm{K}^{+}$, while the $\mathrm{Mg}^{2+}$ ion content is relatively low. A relatively high content of anions like $\mathrm{HCO}_{3}{ }^{-}$, while $\mathrm{SO}_{4}{ }^{2-}$ ion content is relatively low. The details are listed in Table 2. The volume fraction of oxygen of the injection air is $21 \%$.

Table 2. Formation water composition (mg/L).

\begin{tabular}{cc}
\hline Ion & Salinity \\
\hline $\mathrm{Na}^{+}+\mathrm{K}^{+}$ & 1493.85 \\
$\mathrm{Ca}^{2+}$ & 10.02 \\
$\mathrm{Mg}^{2+}$ & 6.08 \\
$\mathrm{Cl}^{-}$ & 274.80 \\
$\mathrm{SO}_{4}{ }^{2-}$ & 81.65 \\
$\mathrm{HCO}_{3}^{-}$ & 3051.00 \\
$\mathrm{CO}_{3}{ }^{2-}$ & 195.00 \\
Total Salinity & 5112.42 \\
\hline
\end{tabular}

\subsubsection{Experimental Procedures}

The experiment is divided into eight steps.

(1) The air permeability of the natural core is determined after oil extraction, washing, drying, packaging the core in plastic, connecting it with the core model, and connecting the back pressure controller to the outlet end of core. The porosity is determined after formation water saturation.

(2) Formation water is prepared, the cores are saturated with water, and the water permeability calculated.

(3) Oil is injected into the core which is saturated with water, creating oil flooding water, until there no water comes out of the core outlet, and the irreducible water saturation is calculated.

(4) Water is injected into the core 15 for water flooding until no oil flows out. The amount of oil flooding by water, the amount of injection water needed for the flooding process, and the residual oil saturation, recovery efficiency and ultimate recovery can be calculated.

(5) Core 15 should be oil saturated with irreducible water. Repeat step (3), to calculate the irreducible water saturation.

(6) Inject water into core 15 for water flooding until the water cut of the outlet reaches $75 \%$, which is the average water cut of the block. Adjust the gas pressure to the displacement pressure, inject air into the core for the oil displacement experiments until no oil flows out, calculating the amount of oil and injected air.

(7) Repeat steps (1) (4) to calculate the residual oil saturation, recovery efficiency and ultimate recovery with core 31 .

(8) Repeat steps (1) (3), (6), measuring the oil and gas volume and injected gas volume and calculate the recovery efficiency with core 32 . 


\section{Results and Discussion}

\subsection{Test Conclusions}

The initial exothermal temperature was $200{ }^{\circ} \mathrm{C}$; adiabatic temperature rise $>136{ }^{\circ} \mathrm{C}$; maximum heating rate $0.11^{\circ} \mathrm{C} / \mathrm{min}$; correction coefficient is 2.24 ; activation energy $87.577 \mathrm{~kJ} / \mathrm{mol}$. Refer to the former factor $1.54 \times 10^{8} \mathrm{~s}^{-1}$; reaction series is 0.97 . The adiabatic oxidation process temperature-time profile is shown in Figure 3. As shown in the figure, the current block formation of crude oil, particulate cores and water mixture can happen with the air oxidation reaction in low temperature. At the reservoir temperature, the low temperature oxidation reaction is very slow, less than the rate of diffusion of oxygen into the oil.

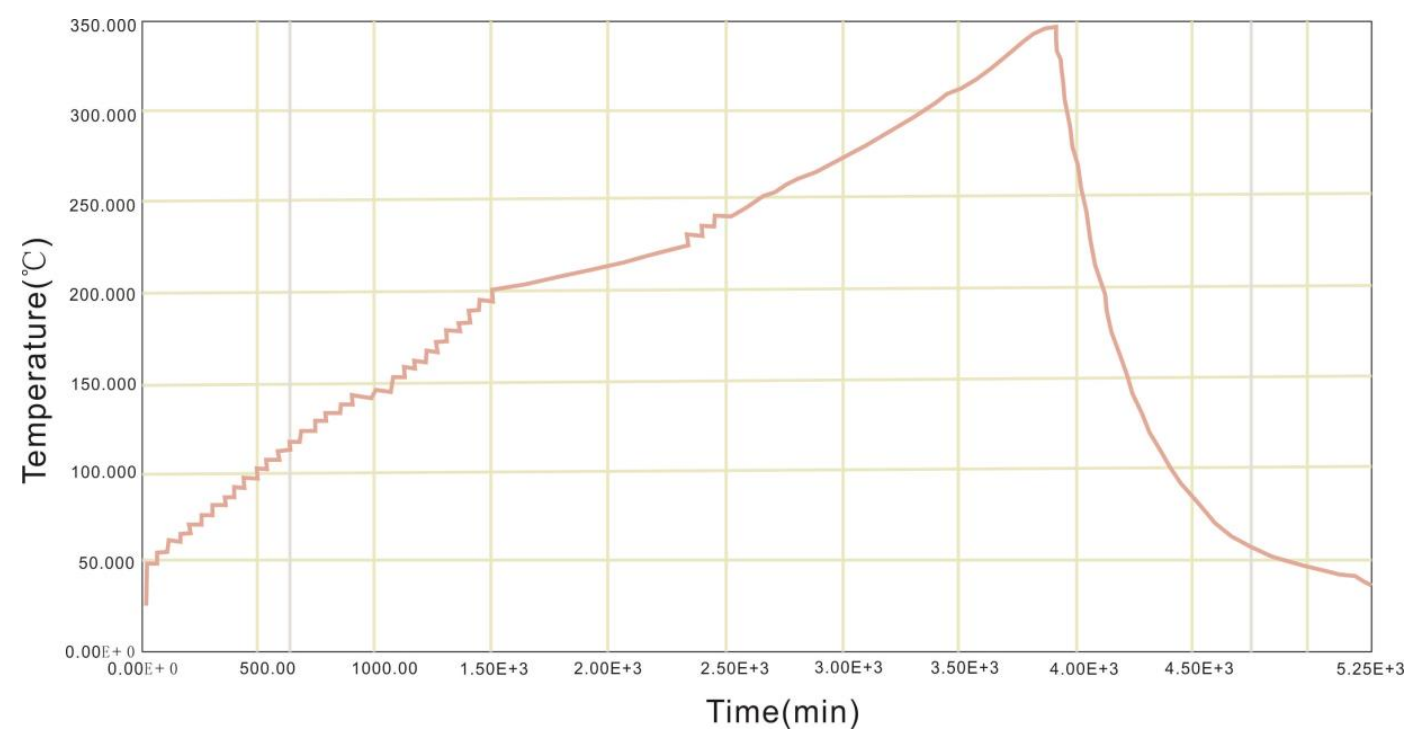

Figure 3. Adiabatic oxidation process temperature-time curve.

The speed can be lower when there are no sands, suggesting that the reaction occurs on the surface of the sand, or when the oil and gas interface is fairly small, and the reaction is controlled by the diffusion.

\subsection{The Experimental Results and Analysis}

There are three groups of oil displacement experiments. The first set of experiments used core 15 for water flooding only, followed by gas flooding after the water flooding experiment; the second set of experiments used core 31 for water flooding; the third set of experiments used core 32 for gas flooding after a water flooding experiment. The current $\mathrm{N}$ block water cut is about $75 \%$, so in order to make the experiment more in line with the reality, the water drive was changed to gas drive as the outlet water cut reached up to $75 \%$.

\subsubsection{The First Set of Experiments}

For the first set of experiments with core 15, the physical parameters of the core are shown in Table 3.

The core was drilled from the 12-16 Well of L oilfield N block. $\mu_{\mathrm{w}}$ is the injected water viscosity, $K_{a}$ is the permeability, $\phi$ is the porosity, $T$ is the experimental temperature, $\gamma_{d}$ the is ratio of formation water, $K_{W}$ is the water phase permeability, $\gamma_{\mathbf{W}}$ is the ratio of injected water and formation water, $\mu_{\mathrm{d}}$ is brine viscosity, $L$ is the core length, $k$ is the water-free oil recovery, the $S_{w i}$ is the irreducible water saturation, $D$ is the diameter, $s_{o r}$ is residual oil saturation, $K_{w}$ is the water phase permeability in the residual oil saturation, $\eta$ is the ultimate oil displacement efficiency of water flooding, $V$ is the 
pore volume, $v_{\mathrm{w}} \mathrm{s}$ the water injection rate, $Q_{o}$ is the oil saturation, $\mu_{o}$ is the oil viscosity, $A$ is the cross-sectional area, and $p_{w o}$ is the differential pressure at the end of the water displacement.

Table 3. Core physical property parameters and experimental conditions.

\begin{tabular}{|c|c|c|c|c|c|c|}
\hline \multicolumn{7}{|c|}{ Parameter } \\
\hline$\mu_{\mathrm{w}} / \mathrm{mPa} \cdot \mathrm{s}$ & $K_{\mathrm{a}} / \times 10^{-3} \mu \mathrm{m}^{2}$ & $\phi / \%$ & $T /{ }^{\circ} \mathrm{C}$ & $\gamma_{d} / \mathrm{g} / \mathrm{cm}^{3}$ & $\mu_{\mathrm{o}} / \mu_{\mathrm{w}} *$ & $K_{\mathrm{w}} / \times 10^{-3} \mu \mathrm{m}^{2}$ \\
\hline 0.65 & 0.74 & 12.63 & 78 & 0.993 & 4.23 & 0.56 \\
\hline \multicolumn{7}{|c|}{ Parameter } \\
\hline$\gamma_{W} / \mathrm{g} / \mathrm{cm}^{3}$ & $\mu_{\mathrm{d}} / \mathrm{mPa} \cdot \mathrm{s}$ & $\mathrm{L} / \mathrm{cm}$ & $k / \%$ & $S_{\mathrm{wi}} / \%$ & $\mathrm{D} / \mathrm{cm}$ & $S_{\text {or }}$ \\
\hline 0.99 & 0.67 & 6.54 & 36.3 & 42.77 & 2.36 & 0.0807 \\
\hline \multicolumn{7}{|c|}{ Parameter } \\
\hline$\eta / \%$ & $V / \mathrm{cm}^{3}$ & $v_{\mathrm{w}} / \mathrm{mL} \cdot \min ^{-1}$ & $Q_{0} / \mathrm{mL}$ & $\mu_{\mathrm{o}} / \mathrm{mPa} \cdot \mathrm{s}$ & $A / \mathrm{cm}^{2}$ & $p_{\mathrm{w} 0} / \mathrm{MPa}$ \\
\hline 56.52 & 3.61 & 0.20 & 2.07 & 2.75 & 4.372136 & 4.018 \\
\hline
\end{tabular}

\section{(a) Permeability to Water}

Core 15 is saturated by formation water and $K_{\mathrm{w}}$ was measured. The experimental results are shown in Table 4, where $t_{a}$ is the time interval, $v$ is the injection rate, $t_{a}$ is the cumulative injection time, the $Q$ is the cumulative injection volume, and $p$ is the differential pressure. During the experimental process, the pressure rose slowly, but as the injection time was extended, the pressure rose with a very slight increases, which shows that there are changes in the pore structure of the core, such as jams caused by clay swelling and particle movement, etc.

Table 4. Saturated water experimental results.

\begin{tabular}{cccccc}
\hline $\boldsymbol{t}_{\boldsymbol{a}} / \mathbf{m i n}$ & $\boldsymbol{v} / \mathbf{m L} \cdot \mathbf{m i n}^{-\mathbf{1}}$ & $\boldsymbol{Q} / \mathbf{m L}$ & $\boldsymbol{p} / \mathbf{M P a}$ & Injection Multiples/PV & $\mathbf{K} / \times \mathbf{1 0}^{-\mathbf{3}} \boldsymbol{\mu m}^{\mathbf{2}}$ \\
\hline 0 & 0.5 & 0 & 0 & 0 & \\
60 & 0.5 & 12.00 & 1.388 & 3.32 & 0.602 \\
30 & 0.5 & 18.00 & 1.394 & 4.99 & 0.599 \\
30 & 0.5 & 24.00 & 1.453 & 6.65 & 0.575 \\
20 & 0.5 & 28.00 & 1.464 & 7.76 & 0.570 \\
20 & 0.5 & 32.00 & 1.475 & 8.86 & 0.566 \\
20 & 0.5 & 36.00 & 1.486 & 9.97 & 0.562 \\
\hline
\end{tabular}

(b) Water Flooding Recovery

The core was saturated with oil and the core irreducible water saturation was measured. It takes $75 \mathrm{~min}$ for the oil to come out of the outlet and after $195 \mathrm{~min}$ the core is saturated with oil. In the oil saturation process, the irreducible water saturation is $42.65 \%$. The detailed experimental data is shown in Table $5, Q_{w}$ is the accumulated water production rate.

Table 5. Saturated oil experimental results.

\begin{tabular}{|c|c|c|c|c|c|c|c|}
\hline$t_{a} / \mathrm{min}$ & $v / \mathrm{mL} \cdot \min ^{-1}$ & $Q / \mathrm{mL}$ & $Q_{\mathrm{w}} / \mathrm{mL}$ & $p / \mathrm{MPa}$ & Injection Volume/PV & $K / \times 10^{-3} \mu \mathrm{m}^{2}$ & Remarks \\
\hline 0 & 0.1 & 0 & 0 & 0 & 0 & 0 & \\
\hline 75 & 0.1 & 15.00 & 1.62 & 1.631 & 4.16 & 0.420 & Oil breakthrough \\
\hline 30 & 0.2 & 21.00 & 1.87 & 1.719 & 5.82 & 0.399 & \\
\hline 30 & 0.4 & 27.00 & 1.97 & 3.348 & 7.48 & 0.410 & \\
\hline 30 & 0.8 & 33.00 & 2.07 & 4.969 & 9.14 & 0.552 & \\
\hline 30 & 1.2 & 39.00 & 2.07 & 8.484 & 10.80 & 0.646 & \\
\hline
\end{tabular}

The water flooding experiment was carried out after saturating with oil, and the recovery efficiency of water flooding was determined. In the water flooding process, it took $8 \mathrm{~min}$ for the water to break through, and the measured water-free oil recovery was $36.23 \%$. It takes $565 \mathrm{~min}$ to the end of water 
flooding with an ultimate recovery of $56.52 \%$, a residual oil saturation of $24.93 \%$ and the water phase permeability is $0.0807 \times 10^{-3} \mu \mathrm{m}^{2}$ under $S_{\text {or }}$ conditions. The experimental results are shown in Table 6 and Figures 4 and 5, where $Q_{o}$ is the cumulative oil production.

Table 6. Water flooding experimental results.

\begin{tabular}{|c|c|c|c|c|c|c|c|}
\hline$t_{a} / \mathrm{min}$ & $v / \mathrm{mL} \cdot \min ^{-1}$ & $Q / \mathrm{mL}$ & $Q_{\mathrm{o}} / \mathrm{mL}$ & $p / \mathrm{MPa}$ & Injection Multiples/PV & Recovery/\% & Remarks \\
\hline 0 & 0.2 & 0 & & 0 & 0 & 0 & \\
\hline 5 & 0.2 & 1.00 & 0.55 & 2.476 & 0.28 & 26.57 & \\
\hline 3 & 0.2 & 1.60 & 0.75 & 2.784 & 0.44 & 36.23 & $\begin{array}{c}\text { Water } \\
\text { breakthrough } \\
\text { (water-free } \\
\text { recovery } 36.23 \% \text { ) }\end{array}$ \\
\hline 7 & 0.2 & 3.00 & 0.95 & 3.092 & 0.83 & 45.89 & \\
\hline 10 & 0.2 & 5.00 & 1.00 & 3.555 & 1.39 & 48.31 & \\
\hline 10 & 0.2 & 7.00 & 1.00 & 3.714 & 1.94 & 48.31 & \\
\hline 20 & 0.2 & 11.00 & 1.05 & 3.747 & 3.05 & 50.72 & \\
\hline 30 & 0.2 & 17.00 & 1.07 & 3.806 & 4.71 & 51.69 & \\
\hline 30 & 0.2 & 23.00 & 1.10 & 3.855 & 6.37 & 53.14 & \\
\hline 30 & 0.2 & 29.00 & 1.10 & 3.798 & 8.03 & 53.14 & \\
\hline 30 & 0.2 & 35.00 & 1.12 & 3.850 & 9.70 & 54.11 & \\
\hline 30 & 0.2 & 41.00 & 1.12 & 3.828 & 11.36 & 54.11 & \\
\hline 30 & 0.2 & 47.00 & 1.15 & 3.844 & 13.02 & 55.56 & \\
\hline 30 & 0.2 & 53.00 & 1.15 & 3.826 & 14.68 & 55.56 & \\
\hline 60 & 0.2 & 65.00 & 1.15 & 3.793 & 18.01 & 55.56 & \\
\hline 60 & 0.2 & 77.00 & 1.15 & 3.905 & 21.33 & 55.56 & \\
\hline 60 & 0.2 & 89.00 & 1.17 & 4.020 & 24.65 & 56.52 & \\
\hline 60 & 0.2 & 101.00 & 1.17 & 3.947 & 27.98 & 56.52 & \\
\hline 60 & 0.2 & 113.00 & 1.17 & 4.018 & 31.30 & 56.52 & \\
\hline
\end{tabular}

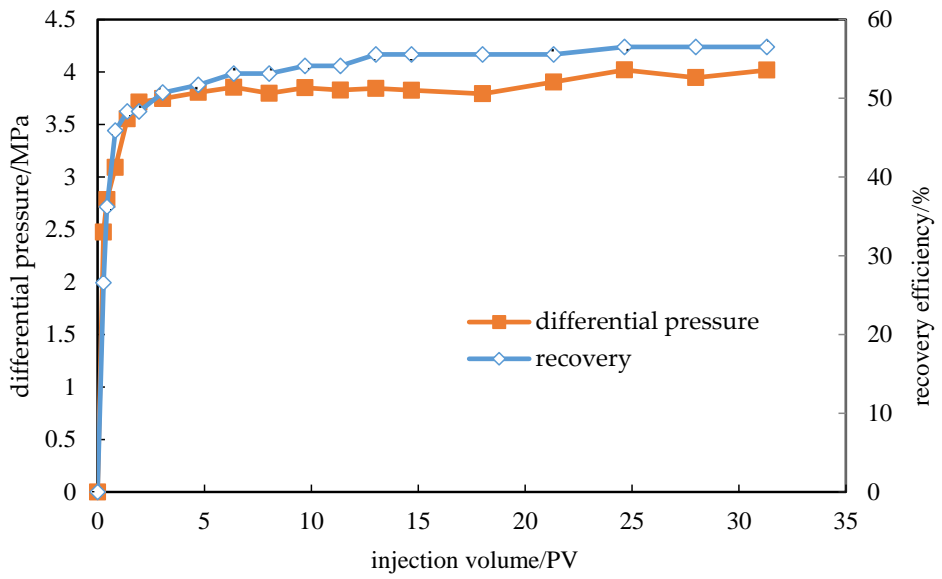

Figure 4. Pressure difference, recovery ratio relationship of injection multiples.

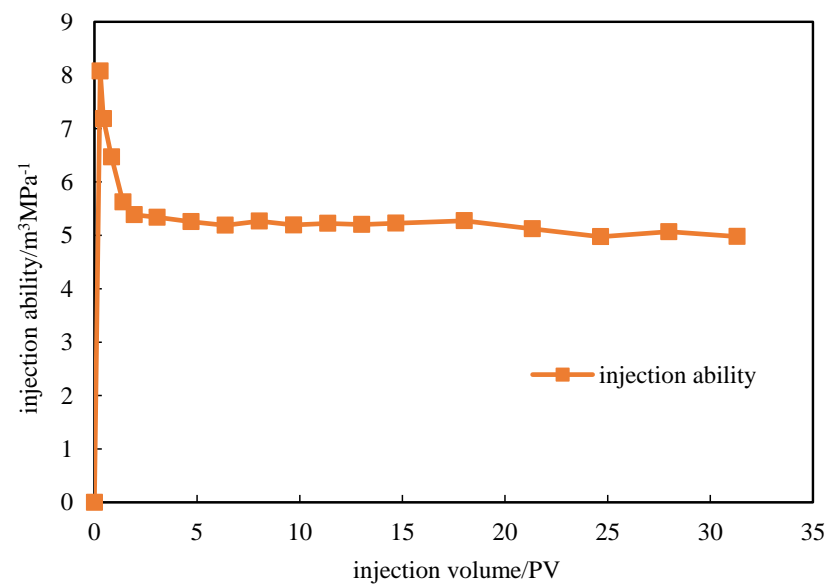

Figure 5. Injection ability and injection multiples relationship diagrams. 
The injection pressure of core 15 during water flooding shows a small fluctuation before rising during the water flooding recovery efficiency experiments, rather than the decreasing pressure seen in general water flooding. The phenomenon illustrates that internal pore blockage happened, which is because of the high content of clay expanding after meeting the water. Generally, the pressure would rise if the open water injection method were adopted, especially in the cores of this block.

The differential pressure between production and injection increased rapidly as the injection volume increased, with the growth slowing down gradually after $0.5 \mathrm{PV}$, and the differential pressure stayed above 3.5 MPa and rose slowly. After 1.5 PV injection, the injection capacity began to flatten, and the injection capacity trended slightly down due to the low permeability of the clay minerals of the core.

\section{(c) Oil Saturation Experiment Again}

Because the structure of core 15 changed after water flooding, the saturated oil pressure is significantly higher than the saturated oil pressure the first time. Due to the decrease of flowing pore volume, the amount of saturated oil was significantly less than the first time, which was high in bound water. The oil measured content was $1.77 \mathrm{~mL}$ in the core, and the irreducible water saturation is $50.97 \%$. Specific experimental data are shown in Table 7 . The experimental purpose is re-saturate the oil with oil, irreducible water, oil content within the core is $1.77 \mathrm{~mL}$, the irreducible water saturation $s_{w i}$ is $50.97 \%$.

Table 7. Saturated oil again experimental results.

\begin{tabular}{|c|c|c|c|c|c|c|c|}
\hline$t_{a} / \mathrm{min}$ & $v / \mathrm{mL} \cdot \min ^{-1}$ & $Q / \mathrm{mL}$ & $Q_{\mathrm{w}} / \mathrm{mL}$ & $p / \mathrm{MPa}$ & Injection Multiples/PV & $K / \times 10^{-3} \mu \mathrm{m}^{2}$ & Remarks \\
\hline 0 & 0.1 & 0 & 0 & 0 & 0 & 0 & \\
\hline 215 & 0.1 & 43.00 & 0.47 & 2.620 & 11.91 & 0.262 & Oil breakthrough \\
\hline 30 & 0.2 & 49.00 & 0.57 & 3.659 & 13.57 & 0.375 & \\
\hline 30 & 0.4 & 55.00 & 0.67 & 5.487 & 15.24 & 0.500 & \\
\hline 30 & 0.8 & 61.00 & 0.77 & 7.288 & 16.90 & 0.753 & \\
\hline 30 & 0.4 & 67.00 & 0.77 & 7.000 & 18.56 & 0.392 & \\
\hline 30 & 0.20 & 73.00 & 0.77 & 6.500 & 20.22 & 0.211 & \\
\hline 30 & 0.10 & 79.00 & 0.77 & 3.587 & 21.88 & 0.191 & \\
\hline 30 & 0.10 & 85.00 & 0.77 & 3.405 & 23.55 & 0.201 & \\
\hline 30 & 0.10 & 91.00 & 0.77 & 3.609 & 25.21 & 0.190 & \\
\hline 60 & 0.10 & 103.00 & 0.77 & 3.688 & 28.53 & 0.186 & \\
\hline 120 & 0.05 & 127.00 & 0.77 & 3.968 & 35.18 & 0.086 & \\
\hline 120 & 0.05 & 151.00 & 0.77 & 4.233 & 41.83 & 0.081 & \\
\hline 120 & 0.05 & 175.00 & 0.77 & 4.564 & 48.48 & 0.075 & \\
\hline 120 & 0.05 & 199.00 & 0.77 & 4.607 & 55.12 & 0.074 & \\
\hline 120 & 0.05 & 223.00 & 0.87 & 4.134 & 61.77 & 0.083 & \\
\hline
\end{tabular}

\section{(d) Air Displacement after Water Flooding Experiments}

First, the experiment was switched from water flooding to gas displacement when the outlet moisture content was $75 \%$. When the injection time is $20 \mathrm{~min}$, outlet water breakthrough occurred and the measured the water-free oil recovery is $35.03 \%$. At the end of the water drive the recovery efficiency was $48.01 \%$. The outlet water cut reached $75 \%$ after the change to air injection. The experiment ended at $185 \mathrm{~min}$, with a total recovery efficiency of $54.80 \%$. Specific experimental data are shown in Table 8 , Figures 6 and 7.

The differential pressure between production and injection increased rapidly as the injection volume increased, and after the injection of air, the differential pressure of injection-production drops rapidly, and stays constant at $2.5 \mathrm{MPa}$. Before the black vertical lines is the water flooding stage, and the gas injection stage is behind. As Figure 6 shows, in the gas flooding after water flooding experiment process, recovery factor increased during the water drive process as the injected water rose significantly. After changing to air injection displacement and using a displacement velocity of $0.2 \mathrm{~mL} / \mathrm{min}$, the recovery increase is not obvious, and the ultimate recovery was $54.8 \%$. 
Table 8. Switch to air injection experimental results.

\begin{tabular}{|c|c|c|c|c|c|c|c|c|c|}
\hline$t_{a} / \mathrm{min}$ & $V / m L \cdot \min ^{-1}$ & $Q / \mathrm{mL}$ & $Q_{0} / \mathrm{mL}$ & $p / \mathrm{MPa}$ & $\begin{array}{c}\text { Injection } \\
\text { Multiples/PV }\end{array}$ & Recovery/\% & $Q_{\mathrm{a}} / \mathrm{m}^{3} \cdot \mathrm{MPa}^{-1}$ & $\begin{array}{l}\text { Oxygen } \\
\text { Content } / \%\end{array}$ & Remarks \\
\hline 0 & 0.2 & 0 & 0 & 0 & 0 & 0 & 0 & - & \multirow{8}{*}{$\begin{array}{c}\text { Water } \\
\text { breakthrough }\end{array}$} \\
\hline 10 & 0.2 & 1.0 & 0.25 & 4.12 & 0.50 & 20.03 & 0.21 & - & \\
\hline 10 & 0.2 & 2.0 & 0.62 & 5.33 & 0.55 & 35.03 & 0.38 & - & \\
\hline 4 & 0.2 & 2.8 & 0.79 & 5.84 & 0.78 & 45.03 & 0.48 & - & \\
\hline 2 & 0.2 & 3.2 & 0.83 & 5.83 & 0.89 & 46.76 & 0.55 & - & \\
\hline 2 & 0.2 & 3.6 & 0.85 & 5.84 & 1.00 & 48.01 & 0.62 & - & \\
\hline 1 & 0.2 & 3.8 & 0.92 & 4.25 & 1.05 & 51.98 & 0.89 & - & \\
\hline 5 & 0.2 & 4.8 & 0.95 & 4.27 & 1.33 & 53.67 & 1.12 & - & \\
\hline 7 & 0.2 & 6.2 & 0.95 & 3.20 & 1.72 & 53.67 & 1.94 & 19.6 & \multirow{8}{*}{$\begin{array}{l}\text { Gas } \\
\text { breakthrough }\end{array}$} \\
\hline 9 & 0.2 & 8 & 0.97 & 2.90 & 2.22 & 54.80 & 2.76 & 17.6 & \\
\hline 10 & 0.2 & 10 & 0.97 & 2.50 & 2.77 & 54.80 & 4.00 & 16.7 & \\
\hline 15 & 0.2 & 13 & 0.97 & 2.50 & 3.60 & 54.80 & 5.20 & 12.1 & \\
\hline 20 & 0.2 & 17 & 0.97 & 2.50 & 4.71 & 54.80 & 6.80 & 10.2 & \\
\hline 25 & 0.2 & 22 & 0.97 & 2.50 & 6.09 & 54.80 & 8.80 & 10.2 & \\
\hline 30 & 0.2 & 28 & 0.97 & 2.50 & 7.76 & 54.80 & 11.20 & 9.9 & \\
\hline 35 & 0.2 & 35 & 0.97 & 2.50 & 9.70 & 54.80 & 14.00 & 7.5 & \\
\hline
\end{tabular}

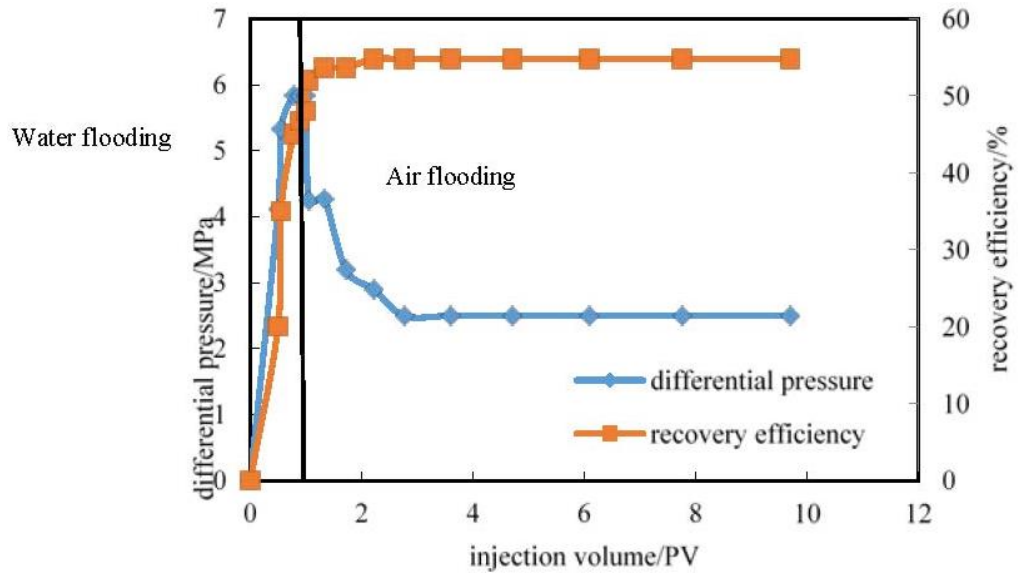

Figure 6. Pressure differential, recovery ratio relationship of multiple injections.

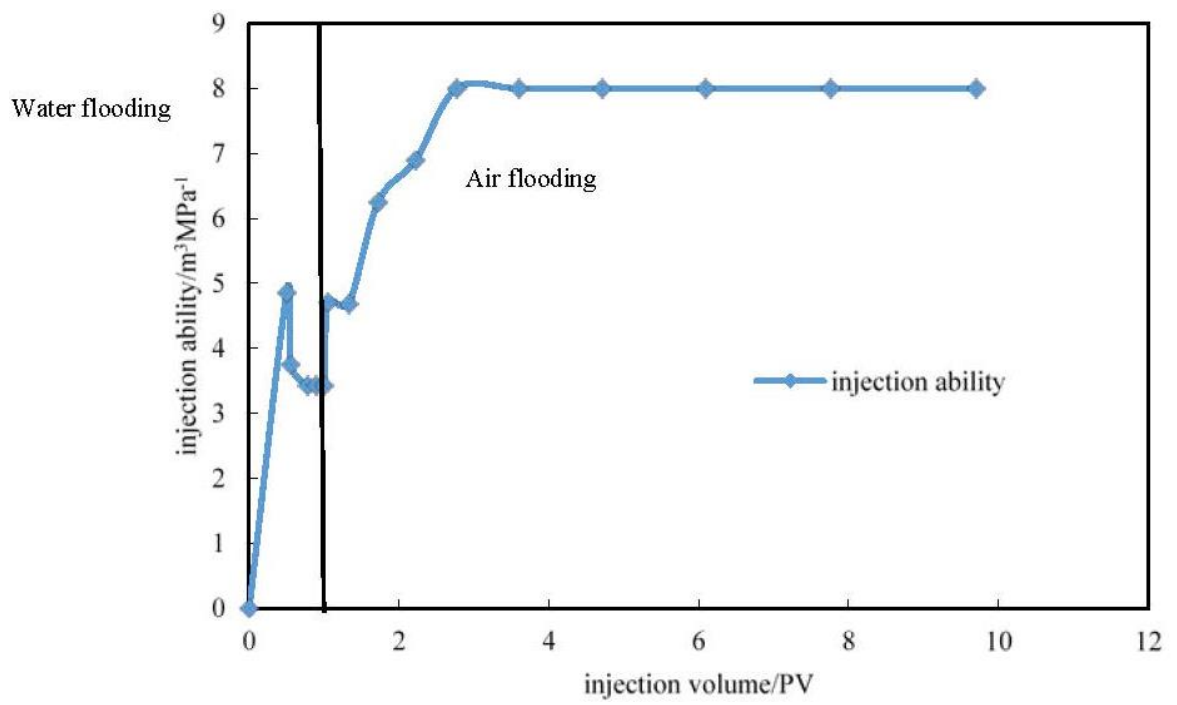

Figure 7. Injection ability and multiple injection relationship diagrams. 
(e) Analysis of the Results

The recovery in core 15 is $56.52 \%$ during the first water flooding experiment process, which is higher than the second water flooding recovery efficiency of $54.80 \%$. As Table 8 shows, the oxygen content is higher after gas breakthrough with an oxygen content of $19.6 \%$, and the oxygen content of the injected air was $21 \%$, suggesting that gas channeling happened during the air displacement process, which affected the results of the experiment. In order to confirm the air displacement effect, a second and the third group of experiments was carried out, and in the bcase of gas channeling the injection volume, and injection solvent amount increased.

\subsubsection{The Second and the Third Groups of Experiments}

The second and third groups of experiments were carried out with cores 31 and 32, respectively. The cores are drilled from 12 to 18 Wells at $3228 \mathrm{~m}$ depth with similar properties, and adopt water flooding and water flooding to air flooding at the water cut of $75 \%$ in the outlet, to make a contrastive analysis of the experimental results. A second group of core 31 basic data used in the experiment are shown in Table 9.

Table 9. The Core 31 physical property parameters and experimental conditions.

\begin{tabular}{|c|c|c|c|c|c|c|c|}
\hline Parameters & $K_{\mathrm{a}} / \times 10^{-3} \mu \mathrm{m}^{2}$ & $\mathrm{~T} /{ }^{\circ} \mathrm{C}$ & $\mu_{\mathrm{o}} / \mu_{\mathrm{w}}{ }^{*}$ & $\phi / \%$ & $\gamma_{d} / \mathrm{g} \cdot \mathrm{cm}^{-3}$ & $K_{\mathrm{w}} / \times 10^{-3} \mu \mathrm{m}^{2}$ & $\mathrm{~L} / \mathrm{cm}$ \\
\hline Value & 3.1825 & 78 & 4.23 & 14.31 & 0.993 & 2.95 & 7.09 \\
\hline Parameters & $\mu_{\mathrm{d}} / \mathrm{mPa} \cdot \mathrm{s}$ & $k / \%$ & $D / \mathrm{cm}$ & $V / \mathrm{cm}^{3}$ & $S_{\mathrm{wi}} / \%$ & $S_{\text {or }}$ & $v_{\mathrm{w}} / \mathrm{mL} \cdot \min ^{-1}$ \\
\hline Value & 0.67 & 37.2 & 2.36 & 4.44 & 40.09 & 0.255 & 0.20 \\
\hline Parameters & $A / \mathrm{cm}^{2}$ & $\mu_{\mathrm{o}} / \mathrm{mPa} \cdot \mathrm{s}$ & $Q_{0} / \mathrm{mL}$ & $p_{\mathrm{WO}} / \mathrm{MPa}$ & $\mu_{\mathrm{w}} / \mathrm{mPa} \cdot \mathrm{s}$ & $\gamma_{\mathrm{w}} / \mathrm{g} \cdot \mathrm{cm}^{-3}$ & $\eta / \%$ \\
\hline Value & 4.372 & 2.75 & 2.66 & 3.853 & 0.65 & 0.99 & 57.51 \\
\hline
\end{tabular}

On core 31 with saturated oil operation, we measured the irreducible water saturation of the core. During the process of oil saturation, after a cumulative injection time of $120 \mathrm{~min}$, oil came out from the outlet. After $210 \mathrm{~min}$ the saturated oil release is over, and the irreducible water saturation measured $40.09 \%$. Specific experimental data are shown in Table 10.

Table 10. Saturated oil experiment results.

\begin{tabular}{cccccccc}
\hline $\boldsymbol{t}_{\boldsymbol{a}} / \mathbf{m i n}$ & $\boldsymbol{v} / \mathbf{m L} \cdot \mathbf{m i n}^{-\mathbf{1}}$ & $\boldsymbol{Q} / \mathbf{m L}$ & $\boldsymbol{Q}_{\mathbf{w}} / \mathbf{m L}$ & $\boldsymbol{p} / \mathbf{M P a}$ & Injection Multiples/PV & $\boldsymbol{K} / \times \mathbf{1 0}^{-\mathbf{3}} \boldsymbol{\mu m}^{\mathbf{2}}$ & Remarks \\
\hline $\mathbf{0}$ & 0.10 & 0 & 0 & 0 & 0 & 0 & \\
$\mathbf{7 0}$ & 0.20 & 14 & 1.03 & 0.89 & 3.15 & 1.67 & \\
$\mathbf{5 0}$ & 0.50 & 24 & 1.65 & 1.53 & 5.41 & 2.43 & Oil found \\
$\mathbf{3 0}$ & 1.20 & 30 & 2.06 & 2.92 & 6.76 & 3.06 & \\
$\mathbf{3 0}$ & 1.80 & 36 & 2.35 & 4.58 & 8.11 & 3.92 & \\
$\mathbf{3 0}$ & 3.15 & 42 & 2.66 & 7.36 & 9.46 & & \\
\hline
\end{tabular}

At the time of 10 min injection, water broke through from the outlet, and the water-free oil recovery was $37.22 \%$. Water flooding ended at $545 \mathrm{~min}$, and the ultimate recovery of $57.52 \%$, and the residual oil saturation was $25.45 \%$. The data are shown in Table 11, Figures 8 and 9.

Table 11. Second group of water flooding experiment results.

\begin{tabular}{ccccccccc}
\hline$t_{a} / \mathbf{m i n}$ & $v / \mathbf{m L} \cdot \mathbf{m i n}^{-\mathbf{1}}$ & $\mathbf{Q} / \mathbf{m L}$ & $Q_{\mathbf{o}} / \mathbf{m L}$ & $\boldsymbol{p} / \mathbf{M P a}$ & $\begin{array}{c}\text { Injection } \\
\text { Multiples/PV }\end{array}$ & Recovery/\% & $Q_{\mathbf{a}} / \mathbf{m}^{\mathbf{3}} \cdot \mathbf{M P a}^{-\mathbf{1}}$ & Remarks \\
\hline 0 & 0.20 & 0 & 0 & 0 & 0 & 0 & 0 & \\
5 & 0.2 & 1.00 & 0.68 & 1.53 & 0.23 & 25.56 & 0.65 & Water \\
5 & 0.2 & 2.00 & 0.99 & 2.68 & 0.45 & 37.22 & 0.75 & breakthrough \\
7 & 0.2 & 3.40 & 1.00 & 2.89 & 0.77 & 37.59 & 1.18 & \\
\hline
\end{tabular}


Table 11. Cont.

\begin{tabular}{|c|c|c|c|c|c|c|c|c|}
\hline$t_{a} / \mathrm{min}$ & $v / \mathrm{mL} \cdot \min ^{-1}$ & $Q / \mathrm{mL}$ & $Q_{\mathrm{o}} / \mathrm{mL}$ & $p / \mathrm{MPa}$ & $\begin{array}{c}\text { Injection } \\
\text { Multiples/PV }\end{array}$ & Recovery/\% & $Q_{\mathrm{a}} / \mathrm{m}^{3} \cdot \mathrm{MPa}^{-1}$ & Remarks \\
\hline 10 & 0.2 & 5.40 & 1.00 & 3.33 & 1.22 & 37.59 & 1.62 & \\
\hline 15 & 0.2 & 8.40 & 1.00 & 3.56 & 1.89 & 37.59 & 2.36 & \\
\hline 20 & 0.2 & 12.40 & 1.05 & 3.68 & 2.79 & 39.47 & 3.37 & \\
\hline 30 & 0.2 & 18.40 & 1.05 & 3.78 & 4.14 & 39.47 & 4.87 & \\
\hline 3 & 0.2 & 24.40 & 1.10 & 3.78 & 5.50 & 41.35 & 6.46 & \\
\hline 30 & 0.2 & 30.40 & 1.10 & 3.78 & 6.85 & 41.35 & 8.04 & \\
\hline 30 & 0.2 & 36.40 & 1.11 & 3.85 & 8.20 & 41.73 & 9.45 & \\
\hline 30 & 0.2 & 42.40 & 1.27 & 3.83 & 9.55 & 47.74 & 11.08 & \\
\hline 30 & 0.2 & 48.40 & 1.27 & 3.84 & 10.90 & 47.74 & 12.59 & \\
\hline 30 & 0.2 & 54.40 & 1.30 & 4.11 & 12.25 & 48.87 & 13.24 & \\
\hline 60 & 0.2 & 66.40 & 1.36 & 4.61 & 14.95 & 51.13 & 14.40 & \\
\hline 60 & 0.2 & 78.40 & 1.48 & 4.45 & 17.66 & 55.64 & 17.62 & \\
\hline 60 & 0.2 & 90.40 & 1.50 & 4.89 & 20.36 & 56.39 & 18.49 & \\
\hline 60 & 0.2 & 102.4 & 1.53 & 5.03 & 23.06 & 57.52 & 20.36 & \\
\hline 60 & 0.2 & 114.4 & 1.53 & 5.12 & 25.77 & 57.52 & 22.34 & \\
\hline
\end{tabular}

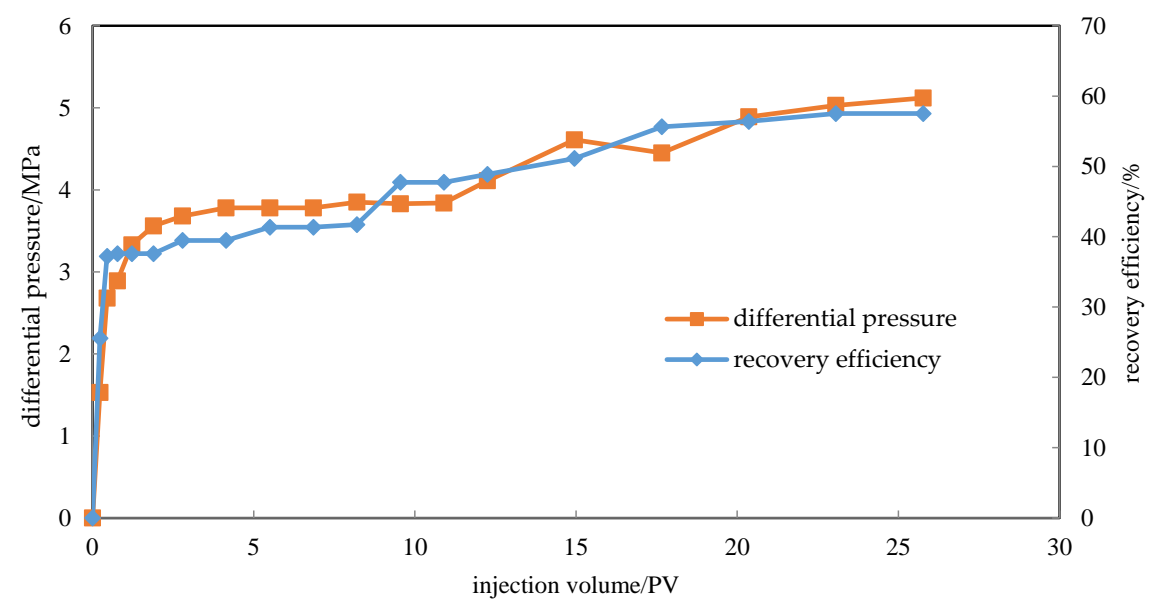

Figure 8. Pressure differential, recovery relationship of multiple injections.

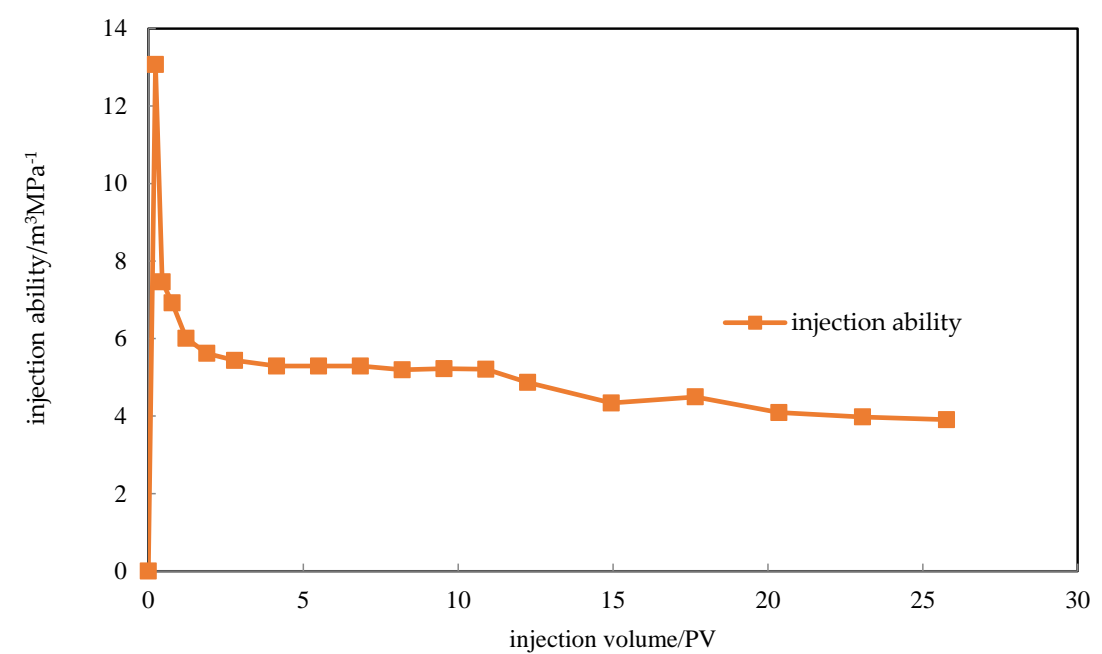

Figure 9. Injection ability and multiple injection relationship diagrams.

The recovery efficiency increased with the increase of injection rate, while the differential pressure between production and injection became higher and higher. For water flooding an ultra-low permeability core, the trend is obviously that the injection capability declines after reaching stability. 
The basic data of core 32 in the third set of experiments are shown in Table 12. The core source was from L oilfield N block Well12-18 (depth $3228 \mathrm{~m}$ ).

Table 12. The core 32 physical property parameters and experimental conditions.

\begin{tabular}{|c|c|c|c|c|c|c|}
\hline \multicolumn{7}{|c|}{ Parameters } \\
\hline$K_{\mathrm{a}} / \times 10^{-3} \mu \mathrm{m}^{2}$ & $\phi / \%$ & $T /{ }^{\circ} \mathrm{C}$ & $\gamma_{d} / \mathrm{g} / \mathrm{cm}^{3}$ & $\mu_{\mathrm{o}} / \mu_{\mathrm{w}}$ & $K_{\mathrm{w}} / \times 10^{-3} \mu \mathrm{m}^{2}$ & $\mathrm{~L} / \mathrm{cm}$ \\
\hline 3.2297 & 14.21 & 78 & 0.993 & 4.23 & 2.83 & 6.08 \\
\hline \multicolumn{7}{|c|}{ Parameters } \\
\hline$\mu_{\mathrm{d}} / \mathrm{mPa} \cdot \mathrm{s}$ & $\mathrm{D} / \mathrm{cm}$ & $S_{\mathrm{wi}} / \%$ & $k / \%$ & $S_{\text {or }}$ & $V / \mathrm{cm}^{3}$ & $v_{\mathrm{w}} / \mathrm{mL} \cdot \min ^{-1}$ \\
\hline 0.67 & 2.36 & 39.78 & 36.4 & 0.241 & 3.78 & 0.20 \\
\hline \multicolumn{7}{|c|}{ Parameters } \\
\hline$A / \mathrm{cm}^{2}$ & $\mu_{\mathrm{o}} / \mathrm{mPa} \cdot \mathrm{s}$ & $Q_{0} / \mathrm{mL}$ & $p_{\mathrm{WO}} / \mathrm{MPa}$ & $\mu_{\mathrm{w}} / \mathrm{mPa} \cdot \mathrm{s}$ & $\gamma_{W} / \mathrm{g} / \mathrm{cm}^{3}$ & $\eta / \%$ \\
\hline 4.372 & 2.75 & 2.28 & 2.211 & 0.65 & 0.99 & 60.09 \\
\hline
\end{tabular}

(a) Water Flooding Recovery

Core 32 was saturated with oil, and the irreducible water saturation of the core was measured. During the process of oil saturation, at the injection time of $220 \mathrm{~min}$, oil breakthrough from outlet was observed. The saturation was over at $610 \mathrm{~min}$, and the irreducible water saturation was $39.78 \%$. Specific experimental data are shown in Table 13.

Table 13. Third oil saturation experiment results of experiments.

\begin{tabular}{cccccccc}
\hline $\boldsymbol{t}_{\boldsymbol{a}} / \mathbf{m i n}$ & $\boldsymbol{v} / \mathbf{m L} \cdot \mathbf{m i n}^{-\mathbf{1}}$ & $\boldsymbol{Q} / \mathbf{m L}$ & $\boldsymbol{Q}_{\mathbf{w}} \mathbf{m} \mathbf{m L}$ & $\boldsymbol{p} / \mathbf{M P a}$ & Injection Multiples/PV & $\boldsymbol{K} / \times \mathbf{1 0}^{-\mathbf{3}} \boldsymbol{\mu m}^{\mathbf{2}}$ & Remarks \\
\hline 0 & 0.1 & 0 & 0 & 0 & 0 & 0 & \\
50 & 0.2 & 10 & 1.03 & 0.99 & 2.65 & 1.29 & \\
70 & 0.2 & 24 & 1.11 & 1.2 & 6.35 & 1.06 & Oil \\
50 & 0.3 & 34 & 1.37 & 1.47 & 8.99 & 1.30 & breakthrough \\
50 & 0.4 & 44 & 1.54 & 1.56 & 11.64 & 0.92 & \\
30 & 0.4 & 50 & 1.66 & 2.78 & 13.23 & 1.11 & \\
30 & 0.5 & 56 & 1.87 & 2.86 & 14.81 & 2.18 & \\
30 & 0.5 & 62 & 1.95 & 2.87 & 16.40 & 1.39 & \\
60 & 1 & 74 & 2.01 & 2.92 & 19.58 & 2.58 & \\
60 & 1.6 & 86 & 2.01 & 7.36 & 22.75 & 2.36 & \\
60 & 1.8 & 98 & 2.28 & 7.25 & 25.93 & & \\
120 & 3.2 & 122 & 2.28 & 8.64 & 32.28 & &
\end{tabular}

(b) Switch to Air Displacement after Water Flooding Experiment

A gas flooding after water flooding experiment was carried out on core 32. The water flooding experiment was performed first, until the outlet water cut is $75 \%$, and then switched to a gas displacement experiment. When the injection time is $15 \mathrm{~min}$, water breaks through from outlet, and the water-free oil recovery is $36.40 \%$. The water flooding experiment ended at 26 min, and the recovery from the core was $50.10 \%$. Then it was converted to a gas displacement experiment, and gas breakthrough from the outlet was observed at $34 \mathrm{~min}$, so as the instantaneous flow became faster, gas breakthrough occurs sooner, and there is a sharp drop in pressure. The gas flooding experiment ended at $119 \mathrm{~min}$, and the recovery was $60.09 \%$. The results are shown in Table 14, Figures 10 and 11.

Compared to the second set of experiments, the differential pressure of injection-production drops by more than half after the air drive, which matches with the first set of experiments. The area before the black vertical line is the water flooding stage, and the gas injection stage follows. The injection capacity increased more than one time and remained stable after air flooding, which matches the first set of experiments. Several researchers' results [24] show that for most of the oil product, the oxygen content safety limit is $10 \% \sim 11 \%$. As shown in Table 14, the oxygen content is $10.8 \%$, which is within the safety scope of the security. At the same time, the well spacing between injection and production 
well is generally a few hundred meters, so the oxygen of the injected air could make full contacted with the oil within the scope of the long distance, and result in a slow reaction at the reservoir temperature, so the concentration of oxygen is reduced gradually, so we can predict that the production well will not explode, but the surveillance must nevertheless be strengthened $[25,26]$.

Table 14. Third group experiment: first water flooding followed by air injection experiments.

\begin{tabular}{|c|c|c|c|c|c|c|c|c|c|}
\hline$t_{a} / \mathrm{min}$ & $V / \mathrm{mL} \cdot \min ^{-1}$ & $Q / \mathrm{mL}$ & $Q_{\mathrm{o}} / \mathrm{mL}$ & $P / \mathrm{MPa}$ & $\begin{array}{c}\text { Injection } \\
\text { Multiples/PV }\end{array}$ & Recovery/\% & $Q_{\mathrm{a}} / \mathrm{m}^{3} \cdot \mathrm{MPa}^{-1}$ & $\begin{array}{l}\text { Oxygen } \\
\text { Content } / \%\end{array}$ & Remarks \\
\hline 0 & 0.2 & 0 & 0 & 0 & 0 & 0 & 0 & - & \multirow{9}{*}{$\begin{array}{c}\text { Water } \\
\text { breakthrough }\end{array}$} \\
\hline 5 & 0.2 & 1.00 & 0.62 & 5.36 & 0.26 & 27.19 & 0.19 & - & \\
\hline 10 & 0.2 & 3.00 & 0.83 & 5.84 & 0.79 & 36.40 & 0.51 & - & \\
\hline 5 & 0.2 & 4.00 & 1.04 & 5.90 & 1.06 & 45.47 & 0.68 & - & \\
\hline 2 & 0.2 & 4.40 & 1.12 & 5.96 & 1.16 & 49.20 & 0.74 & - & \\
\hline 2 & 0.2 & 4.80 & 1.13 & 6.21 & 1.27 & 49.65 & 0.77 & - & \\
\hline 2 & 0.2 & 5.20 & 1.14 & 6.35 & 1.38 & 50.10 & 0.82 & - & \\
\hline 1 & 0.2 & 5.40 & 1.15 & 6.40 & 1.43 & 50.44 & 0.84 & - & \\
\hline 2 & 0.2 & 5.80 & 1.19 & 5.89 & 1.53 & 52.19 & 0.98 & - & \\
\hline 5 & 0.2 & 6.80 & 1.23 & 3.14 & 1.80 & 53.95 & 2.17 & 10.8 & \multirow{7}{*}{$\begin{array}{c}\text { Gas } \\
\text { breakthrough }\end{array}$} \\
\hline 5 & 0.2 & 7.80 & 1.27 & 3.02 & 2.06 & 55.70 & 2.58 & 8.7 & \\
\hline 10 & 0.2 & 9.80 & 1.27 & 3.02 & 2.59 & 55.70 & 3.25 & 7.1 & \\
\hline 10 & 0.2 & 11.80 & 1.34 & 2.50 & 3.12 & 58.77 & 4.72 & 7.0 & \\
\hline 10 & 0.2 & 13.80 & 1.34 & 2.50 & 3.65 & 58.77 & 5.52 & 5.6 & \\
\hline 20 & 0.2 & 17.80 & 1.37 & 2.50 & 4.71 & 60.09 & 7.12 & 4.6 & \\
\hline 30 & 0.2 & 23.80 & 1.37 & 2.50 & 6.30 & 60.09 & 9.52 & 4.1 & \\
\hline
\end{tabular}

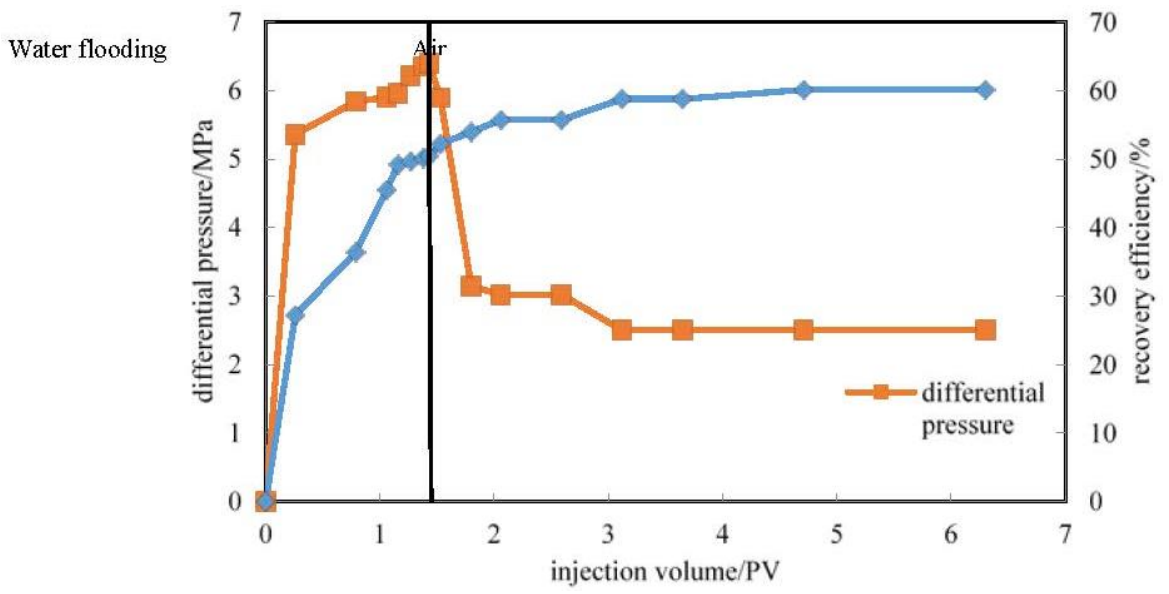

Figure 10. Pressure difference, recovery ratio relationship of multiple injections.

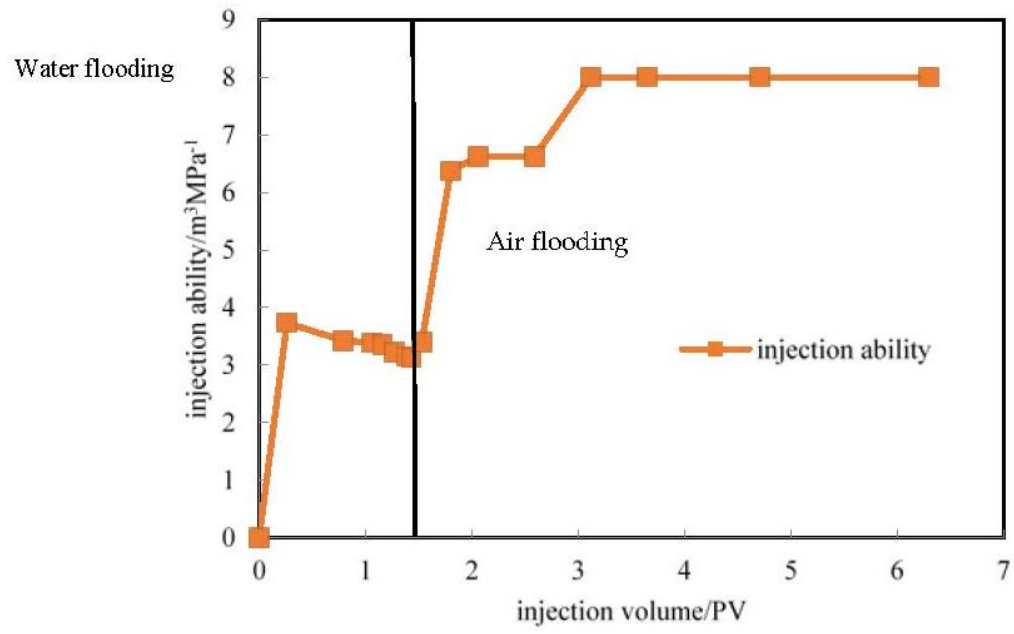

Figure 11. Injection ability and multiple injection relationship diagrams. 
Figure 10 shows that recovery efficiency continues to increase during the water flooding, and the recovery is $45.47 \%$ when the water injection up to $1.06 \mathrm{PV}$ (injection volume divided by pore volume). Then the water flooding effect get worse, and when $1.38 \mathrm{PV}$ is injected, the recovery reaches $50.10 \%$. We switch from water drive to gas drive when the water displacement becomes difficult. The displacement rate is $0.2 \mathrm{~mL} / \mathrm{min}$, injection angle is $20^{\circ}$, and air displacement improved the recovery efficiency to $60.09 \%$ by gravitational force, which is higher than ever.

\section{(c) Result Comparison}

Figure 12 shows that the injection pressure increases obviously after switching to air flooding, and oil recovery with air flooding is higher than with water flooding when the injection up to 4 to $5.5 \mathrm{PV}$. The pressure of the air injection is nearly half lower than the pressure of water flooding, and the pressure falls rapidly after breakthrough. From Figures 13 and 14, the oil displacement ability of water flooding in the two experiments is close, and they show similar recovery trends, but the recovery of the third group experiments with air displacement is significantly higher than in the second set of experiments, which shows that air flooding plays a significant role in this experiment. Through comparison and analysis of the second and the third groups of experiments on core 31 and core 32, respectively, after water flooding and water flooding to a moisture content of $75 \%$ and switching to air displacement, the recoveries were $57.51 \%$ and $60.09 \%$, respectively, a $60 \%$ drop compared to the water, gas injection pressure differential, and the injection capacity increased by $60 \%$, after the change to air injection of $2.43 \mathrm{PV}$, so compared with the same water flooding the degree of recovery increases significantly. The effect of air displacement in the L oilfield $\mathrm{N}$ block oil displacement is significant, the air displacement of oil is feasible, but places a high requirement on technology.

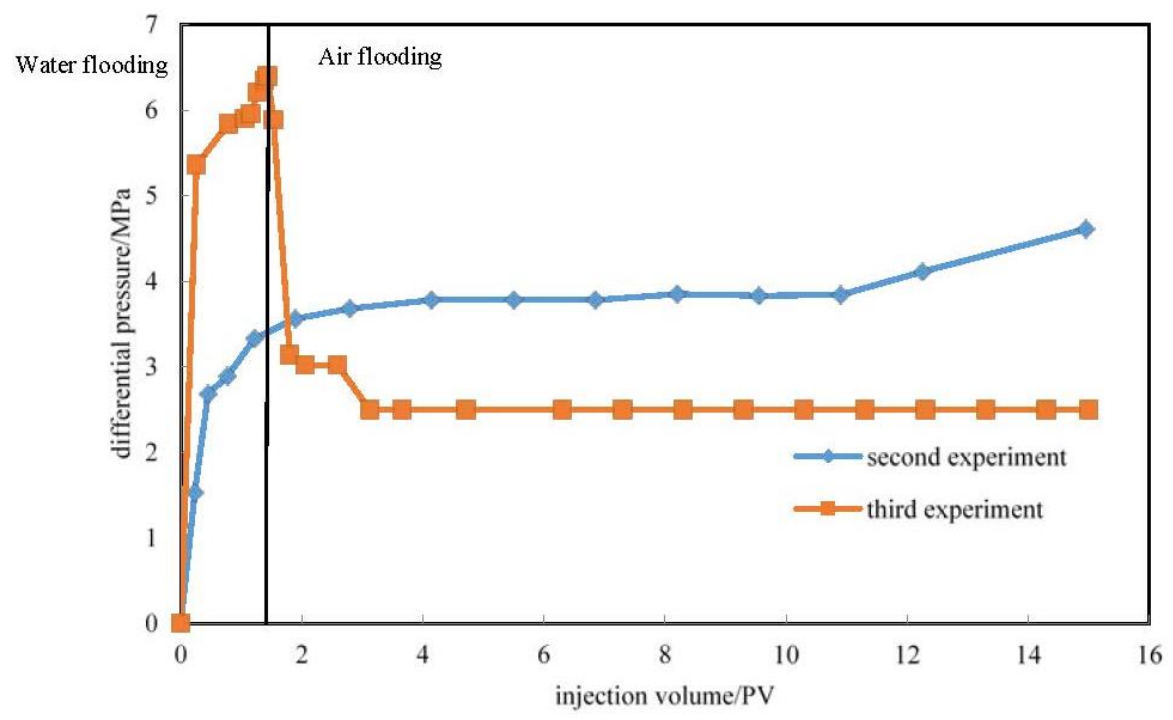

Figure 12. The second and the third group experiments of pressure difference and multiple injection contrast analysis.

The experiments can only consider the viscosity factor, and there is a swept volume in actually water flooding a reservoir, so the actual recovery efficiency is lower than in the experiments. Compared with the $\mathrm{CO}_{2}$ flooding, nitrogen gas flooding is much cheaper, but its security problems are very significant. Corrosion resistance must be considered in the actual production, increasing the monitoring oxygen content.

After the early water flooding stage, the injection of the third set of experiments is more difficult than the second set of experiments, as the differential pressure of injection-production is two times more, and the differential pressure of injection-production is less than only water flooding after 
switching to air flooding. Before the black vertical line is the water flooding stage, and the gas injection stage follows.

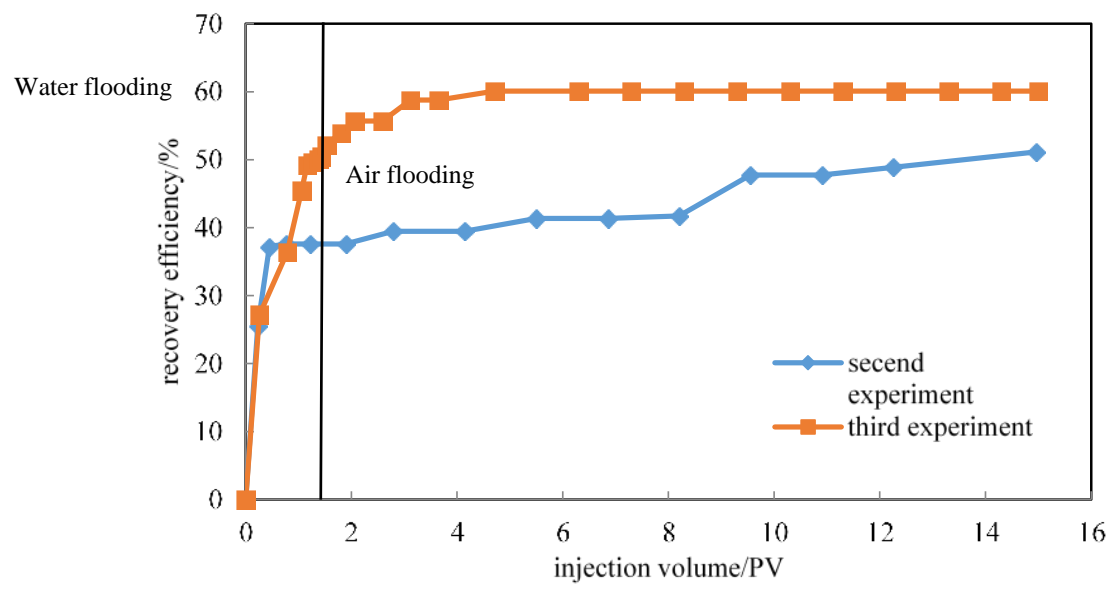

Figure 13. The second and the third group experiments of recovery ratio and multiple injection contrast analysis.

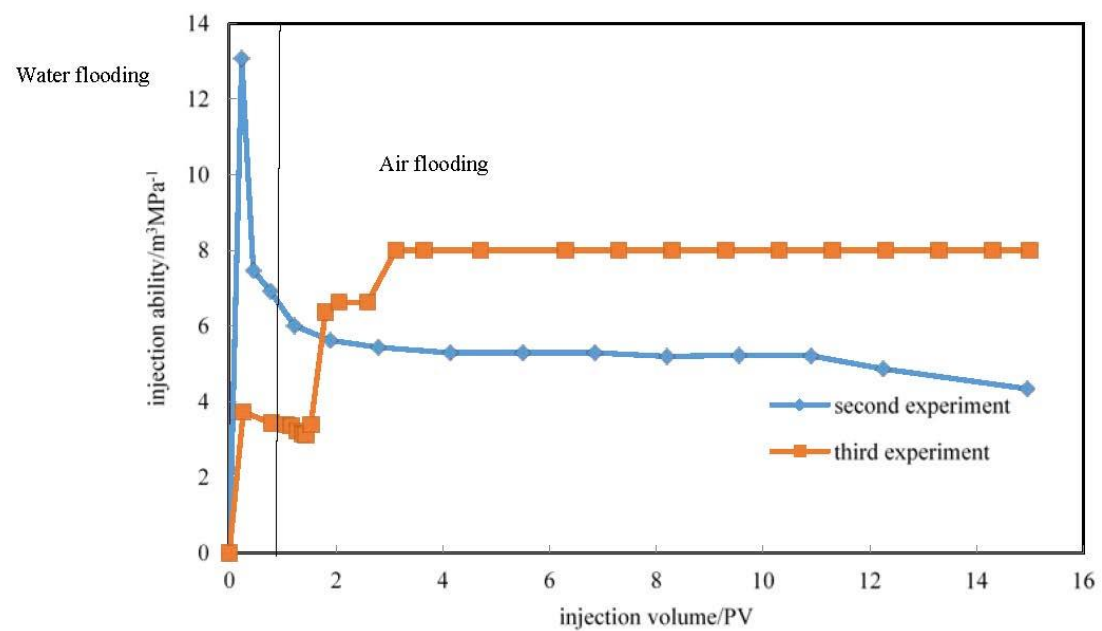

Figure 14. The second and the third group experiments of injection ability and injection multiples contrast analysis.

The injection capacity of the second set of experiments becomes poor gradually, which corresponds to only water flooding, while the injection capacity of the third set of experiments increases greatly after the shift to air flooding. Before the black vertical line is the water flooding stage, and the gas injection stage is behind.

\section{Conclusions}

(1) ARC verified by the experiment that in this block formation oil transformation can happen with low temperature air oxidation, the initial exothermic temperature of the experiment is $240{ }^{\circ} \mathrm{C}$, and the maximum heating rate is $0.11^{\circ} \mathrm{C} / \mathrm{min}$.

(2) The core15 experiments may be a result of gas channeling, and increasing the injection volume, and increasing the sweep efficiency may be ways to improve this problem, and one could also try the injection foam in the actual production.

(3) The recovery efficiency improved $2.58 \%$, the injection-production pressure difference dropped $60 \%$ and the injection capability increased $60 \%$ in the experiment shifting to air flooding after 
water flooding to $75 \%$ moisture content, compared with only water flooding. In the aspect of EOR and injection capacity improvmenet, the air displacement feasibly solved the problem of injection difficulty in the $\mathrm{N}$ fault block of the $\mathrm{L}$ oilfield.

(4) The paper provides experimental proof this can work, suggesting that other science and technology workers could now undertake further tests and verify this through numerical simulation.

Acknowledgments: This work is supported by the Science Foundation of Heilongjiang (QC2016049), the National Natural Science Foundation of China (41572135) and the Major Projects of National Science and Technology of China (2016ZX05046-001 and 2016ZX05010-002-004).

Author Contributions: Guohui Qu and Yuanlin Meng conceived and designed the experiments; Yongxing Tao and Anqi Shen performed the experiments; Yuxin Guo and Anqi Shen analyzed the data; Yikun Liu and Yuanlin Meng contributed reagents; Guohui Qu wrote the paper.

Conflicts of Interest: The authors declare no conflict of interest. Science Foundation of Heilongjiang played a role in the design of the study, National Natural Science Foundation of China played an important role in the collection, analyses and interpretation of data, the Major Projects of National Science and Technology of China played a role in preparation of experiment materials.

\section{References}

1. Greaves, M.; Ren, S.R.; Rathbone, R.R. Air Injection Technique (LTO Process) for IOR from Light Oil Reservoirs: Oxidation. In Proceedings of the SPE/DOE Improved Oil Recovery Symposium, Tulsa, OK, USA, 19-22 April 1998; pp. 479-492.

2. Wang, C.J.; Zheng, L.M.; Gao, R.M. Extra low permeability reservoir in Erdos shallow air flooding after water flooding experiment research. J. Pet. Geol. Eng. 2013, 27, 135-141.

3. Greaves, M.; Ren, S.R.; Rathbone, R.R. Improve Residual Light Oil Recovery by Air Injection (LTO Process). J. Can. Pet. Technol. 2000, 39, 57-61. [CrossRef]

4. Jiang, Y.W.; Zhang, Y.T.; Liu, S.Q. Oil displacement mechanism of air injection of low permeability reservoir development. J. Pet. Explor. Dev. 2010, 37, 471-476.

5. Faure, P.; Landais, P. Evidence for clay minerals catalytic effects during low temperature air oxidation of n-alkanes. J. Fue1 2000, 79, 1751-1756. [CrossRef]

6. Zhang, X.; Liu, J.Y.; Sun, L.T.; Li, S.L.; Liu, W.H. Research on the mechanisms of enhancing recovery of light-oil reservoir by air-injected low-temperature oxidation technique. Nat. Gas Ind. 2004, 24, 78-80.

7. Sandra, R.; Nielsen, R.F. Tibetan Mining Dynamics; Petroleum Industry Press: Beijing, China, 1987; pp. 64-137.

8. Dai, Z.; Middleton, R.; Viswanathan, H.; Fessenden-Rahn, J.; Bauman, J.; Pawar, R.; Lee, S.; McPherson, B. An integrated framework for optimizing $\mathrm{CO}_{2}$ sequestration and enhanced oil recovery. Environ. Sci. Technol. Lett. 2014, 1, 49-54. [CrossRef]

9. Ampomah, W.; Balch, R.S.; Grigg, R.B.; McPherson, B.; McPherson, B.; Will, R.A.; Lee, S.; Dai, Z.; Pan, F. Co-optimization of $\mathrm{CO}_{2}$-EOR and storage processes in mature oil reservoirs. Greenhouse Gas Sci. Technol. 2016, 6, 1-15. [CrossRef]

10. Dai, Z.; Viswanathan, H.; Middleton, R.; Pan, F.; Ampomah, W.; Yang, C.; Jia, W.; Xiao, T.; Lee, S.; McPherson, B.; et al. $\mathrm{CO}_{2}$ Accounting and Risk Analysis for $\mathrm{CO}_{2}$ Sequestration at Enhanced Oil Recovery Sites. Environ. Sci. Technol. 2016, 50, 7546-7554. [CrossRef] [PubMed]

11. Giacchetta, G.; Leporini, M.; Marchetti, B. Economic and environmental analysis of a Steam Assisted Gravity Drainage (SAGD) facility for oil recovery from Canadian oil sands. Appl. Energy 2014, 142, 1-9. [CrossRef]

12. Crivellini, A.; Giacchetta, G.; Marchetti, B.; Marchetti, C.; Paciarotti, C.; Terenzi, A. Development and validation of a model for the simulation of the air drying phenomena in pipelines. Int. J. Math. Model. Numer. Optim. 2013, 4, 351-373. [CrossRef]

13. Chen, Y.R.; Guo, P.; Zhang, J.D.; Xiong, J. Low permeability oil reservoir air injection low-temperature oxidation mechanism of crude oil. J. Chongqing Inst. Technol. 2013, 15, 101-103.

14. Permain, P.; Gevelin, J.L. Air Injection into a Light Oil Reservoir: The Horse Creek Project. In Proceedings of Middle East Oil Show and Conference, Manama, Bahrain, 15-18 March 1997.

15. Fu, Z.J. Bohai South, 36 Pieces of Air Displacement Indoor Experimental Research; China University of Petroleum: Beijing, China, 2008. 
16. Fraim, M.L.; Moffitt, P.D.; Yannimaras, D.V. Laborary Testing and Simulation Results for High Pressure Air Injection in a Waterflooded North Sea Oil Reservoir. Available online: http://cat.inist.fr/ ?aModele= afficheN\&cpsidt=6244813 (accessed on 5 September 2016).

17. Moore, R.G.; Ursenbach, M.G. Air injection for oil recovery. J. JCPT 2002, 9, 16-19.

18. Gutierrez, D.; Miller, R.J.; Taylor, A.R.; Pete, T.; Vinodh, K. Buffalo Field High-Pressure Air Injection Projects 1977 to 2007: Technical Performance and Operational Challenges. SPE Reservoir Eval. Eng. 2009, 12, 542-550. [CrossRef]

19. Gutierrez, D.; Miller, R.J.; Taylor, A.R.; Thies, P.; Kumar, V. The Challenge of Predicting The Field Performance of Air Injection Projects -based on Laboratory and Numerical Modeling. J. CPT 2009, 48, 53-56.

20. Fasishi, M.B. Low temperature oxidation of visions crude oils. SPE Reservoir Eng. 1990, 5, 609-616. [CrossRef]

21. Pan, Y.; Dong, W.J.; Feng, L. Physical model visualization model of multi-layer sandstone reservoir water flooding experiment study. J. Southwest Pet. Univ. 2012, 34, 79-86.

22. He, W.X.; Yang, Y.Q.; Ma, C.Y. Law of low permeability reservoir water flooding experiment research. J. Lithologic Reservoir 2010, 22, 109-111.

23. Lv, W.F.; Leng, Z.P.; Zhang, Z.B. Application of CT scanning technology study of water flooding low permeability core mechanism. Geol. Oil Recover. Oil Gas 2013, 20, 87-90.

24. Wan, C.L.; Wang, L. The upper limit value of combustible gas oxygen content security study. Chin. J. Safety Sci. 1999, 9, 48-52.

25. Wang, R.F.; Sun, W. Low permeable sandstone microscopic model of water flooding experiment factors affecting oil displacement efficiency. Geol. Oil Exp. 2010, 32, 93-97.

26. Gao, H.; Sun, W.; Lu, Y.; Tian, Y.H.; Ren, G.F. Experimental study on micro-flow channel characteristic of ultralow permeability sandstone reservoir: Taking Yanchang formation, Ordos Basin as example. Pet. Geol. Recover. Effic. 2011, 18, 58-62.

(C) 2016 by the authors; licensee MDPI, Basel, Switzerland. This article is an open access article distributed under the terms and conditions of the Creative Commons Attribution (CC-BY) license (http://creativecommons.org/licenses/by/4.0/). 